Revista Água Viva

ISSN 1678-7471

\title{
UMA ANÁLISE LITERÁRIA DA REPRESENTAÇÃO DAS PERSONAGENS FEMININAS NO CONTO SENTIMENTO, DE MOREIRA CAMPOS
}

\section{A LITERARY ANALYSIS OF THE REPRESENTATION OF FEMININE CHARACTERS IN THE TALE SENTIMENTO, BY MOREIRA CAMPOS}

\author{
Francisco Jeimes de Oliveira Paiva ${ }^{1}$ \\ Eduardo Dias da Silva ${ }^{2}$
}

Recebido em: 26 set. 2018

Aceito em: 19 dez. 2018

DOI 10.26512/aguaviva.v3i3.24877

RESUMO: O presente texto objetivou analisar o desenlace narrativo e o fluxo de consciência das personagens femininas de Moreira Campos, sobretudo as relações humanas e sociais efetivas pelas personagens de Alice e D. Neide no conto Sentimento (1993). Em uma análise pormenorizada, considera-se à luz da crítica literária que Moreira Campos, além de grande contista do Estado do Ceará, é um dos expoentes da crítica literária, tendo como base as pesquisas de Monteiro (1980), Albuquerque (1985); Melo (2009), Pontes (2011), Timbó \& Coutinho (2012), Elesbão \& Silva (2015), dentre outras. Em síntese, constatou-se que a linguagem da obra desse escritor no processo de (re)criação literário, expressa-se em um diferencial formal, estrutural, estilístico e de expressão escrita, ou seja, o estilo de Moreira Campos se apresenta nítido, adequado, natural em períodos curtos e diretos.

Palavras-chave: Moreira Campos; Crítica Literária; Personagens Femininas.

ABSTRACT: This paper aimed to analyze the narrative outcome and the stream of consciousness of the female characters of Campos Moreira, especially human and social relations effective the characters of Alice D. Neide in the tale Sentimento (1993). In a detailed analysis, it is considered in the light of literary criticism that Moreira Campos, besides being a great short story writer of the State of Ceará (Brazil), is one of the exponents of literary criticism, based on Monteiro (1980), Albuquerque (1985); Melo (2009), Pontes (2011), Timbó \& Coutinho (2012), Elesbão \& Silva (2015), among others. In summary, it was found that the

\footnotetext{
${ }^{1}$ Mestre pelo Programa Interdisciplinar em História e Letras na Faculdade de Educação, Ciências e Letras do Sertão Central (FECLESC), campus da Universidade Estadual do Ceará. Professor de Língua Portuguesa/Literaturas da Secretaria de Educação Básica do Estado do Ceará. E-mail: geimesraulino@yahoo.com.br

${ }^{2}$ Doutorando em Literatura e Mestre em Linguística Aplicada pela Universidade de Brasília (UnB). Professor e Pedagogo na Educação Básica da Secretaria de Estado de Educação do Distrito Federal (SEEDF). Pesquisador nos grupos CNPq FORPROLL e GIEL. E-mail: edu_france2004@yahoo.fr
} 
language of this writer's work in the process of literary (re)creation is expressed in a formal, structural, stylistic and written expression differential, that is, the style of Moreira Campos is clear, appropriate, natural and direct in short periods.

Keywords: Moreira Campos; Literary criticism; Female Characters.

\section{INTRODUÇÃO}

Ela, Alice, mulher, como D. Neide bem via, que não saía de casa, a não ser para seu trabalho. (CAMPOS, 1993, p.354).

O desenvolvimento deste texto nos fez refletir a importância e a interpretação da produção literária de contos, escritos por Moreira Campos, tematizando, sobretudo, as muitas relações sociais construídas na cotidianidade, sem lançar mão de uma linguagem esteticamente objetiva, descritiva e com precisão vocabular, resultando em uma construção narrativa que dialoga com a realidade social das personagens delineadas em sua inteireza psicológica através dos sentimentos humanos que lhes são permeadas pela desgraça, sofrimento, baixeza moral e precariedade humana (ELESBÃO; SILVA, 2015). Pois, como elucidado por Silva (2017, p. 100),

Aquilo que acontece quando se interpreta um texto é o que acontece quando se procura entender qualquer coisa em nosso mundo sociocultural, seja $\mathrm{o}$ significado da vida ou uma interpretação mais comum dos objetos do cotidiano, das ideias e situações. Com isso, a leitura é interpretação, olhar é interpretação, pensar é interpretação; interpretação não é uma atividade especial restrita à elucidação de textos difíceis, ela é um aspecto de todas as formas do entendimento humano.

Retomamos, a princípio, as palavras do prof. José Leite Jr. do Departamento de Literatura da Universidade Federal do Ceará (UFC) ao dizer que Moreira Campos é um neorrealista ou neonaturalista, pelo fato de que abraçou "uma postura crítico-reflexiva diante do modelo oferecido pela sociedade construído sobre bases burguesas”, por esta razão, “o 
grande tema do conto de Moreira Campos é a dignidade humana colocada em prova" (LEITE JÚNIOR, 2014, s/p) ${ }^{3}$.

A fortuna crítica sobre Moreira Campos, que foi citada ao longo de nossa análise, considera que José Maria MOREIRA CAMPOS (doravante MC) é um dos muitos críticos literários, considerado o maior contista cearense de todos os tempos, nasceu em Senador Pompeu, cidade localizada no interior do estado, como elucidado por Melo (2009) e Timbó \& Coutinho (2012). Com uma infância difícil, desde cedo se encantou com o universo das Letras, durante os primeiros anos escolares, foi um leitor voraz de romances, como por exemplo: $O s$ três mosqueteiros, $O$ conde de Monte Cristo, Vinte anos depois, O Visconde de Bragelonne, $O$ Guarani, O moço loiro, As pupilas do senhor Reitor, Inocência, segundo relatos do Porta de Academia, (1989).

Nesse sentido, Pontes (2011) nos traz uma historiografia literária muito importante sobre esse renomado escritor das vidas marginais (1949)

\begin{abstract}
Moreira Campos - (MC) é um dos mais expressivos ficcionistas cearenses. Na arte do conto, afigura-se como um expoente entre os escritores de sua geração, tornando-se o contista cearense de maior projeção nacional. Mesmo tendo produzido sua obra a partir da segunda metade do Século XX, somente poucos anos antes da sua morte (1994), suas obras despertaram um maior interesse da crítica universitária de sua terra. E, de fato, entre pesquisadores do Mestrado em Literatura da Universidade Federal do Ceará, onde naturalmente se esperava isso (PONTES, 2011, p. 15).
\end{abstract}

Alinhado à historiografia acima, Monteiro (1980, p. 15) em uma obra expoente $O$ discurso literário de Moreira Campos sugere uma divisão da produção de contos de MC em dois momentos. O primeiro estaria mais concentrado na "trama narrativa", e o segundo, na "figuração descritiva". Tal desenvolvimento, como se percebe, comprova que o contista cearense seguiu a tendência contemporânea para a concisão narrativa.

Em uma ou em outra fase, de acordo com Monteiro (1980), o contista mantém seu senso de captação do real, ou seja, uma concepção de arte clássico-realista. À primeira fase, mais analítica, Monteiro (1980) e Pereira (2011) nomeiam impressionista; à segunda, mais

\footnotetext{
${ }^{3}$ Depoimento pessoal na Palestra proferida na $30^{\mathrm{a}}$ edição dos Encontros Literários Moreira Campos, tendo como temas as personagens do contista, 2014.
} 
concisa, seria a realista. Ainda segundo esses autores, estariam na primeira fase os títulos Vidas Marginais (1949) e Portas fechadas (1957); em transição, As vozes do morto (1963); e na fase realista, O puxador de terço (1969) e Os doze parafusos (1978), só para citamos alguns exemplos.

Na leitura dos autores Campos, Barroso e Maia (1996) o modo como surgiram os contos de MC, explica-se da seguinte forma:

[...] nenhum conto meu surge da fantasia. Há sempre um ponto verdadeiro, real que eu procuro transformar num conto. Se procuro transformar num conto, já estou compromissado com a arte literária, porque não é só contar o fato simplório, simples: Fulano de tal chegou em casa, viu a mulher em adultério, puxou o revólver [...]. Isto não é arte, é registro policial. A arte tem outra dimensão, é recriação do real. Aí cabe ao autor ter capacidade para dar beleza, chamamento, é a recriação do real (CAMPOS; BARROSO; MAIA, 1996, p. 89).

A linguagem da obra desse escritor no processo de recriação literário, expressa-se em um diferencial formal, estrutural, estilístico e de expressão escrita. Para reforçar tal aspecto Moraes (2004, p. 99), afirma que o estilo de MC se apresenta "nítido, adequado, natural em períodos curtos e talhantes". Por sua vez, Albuquerque (1985) analisa que quanto a linguagem e o estilo, tem-se

uma das peculiaridades dominantes de Moreira Campos consiste na sua maneira sutil de instilar nos seus tipos e personagens centrais a desilusão, a angústia, a dor, o sofrimento, o amor, a paixão e a crueldade. O absurdo da vida acha-se ironicamente enfocado nas injustiças sociais em que se encontram tantos seres humanos marginalizados [...] em expressivos momentos da realidade, o contista deixa que transpareçam pelas sensações íntimas magistralmente descritos e estruturados numa linguagem curta, direta, concisa e dinâmica. Às vezes, a linguagem por ele empregada apresenta-se repleta de adjetivos comedidos, construções nominais e sinestesias. Os contos, narrados no imperfeito, expressam ideia de continuidade e duratividade. Os enfoques descritivos servem de pano-de-fundo para a composição (ALBUQUERQUE, 1985, p. 152-153).

Avaliamos a partir das particularidades estéticas citadas que em relação ao gênero conto é preciso considerar que MC procurou dar relevância e convergência tanto a teoria e 
quanto a prática do conto, tornando esse processo de criação um processo analítico de sua obra, portanto, um desafio que muitas vezes o autor precisaria "realizar artisticamente o que prega em teoria" (PONTES, 2011, p. 55). Acrescenta-se a isso, ainda que há no texto literário de MC, muitos recursos textuais e estilísticos que apontam caminhos nos quais devem ser analisados aspectos que compõem os contos.

Citemos neste momento, as palavras da romancista Rachel de Queiroz no prefácio ao Dizem que os cães vêem coisas $(1987 ; 1996)$. Ela ressalta que a capricho de MC com relação ao conto se compreende pelo método, ou seja,

Quanto trabalho, quanta ouriversaria, quanto lapidar, transpor, alterar, substituir, riscar, ficar longamente com aquela palavra na ponta dos dedos $-\mathrm{e}$ a palavra não cabe no engaste e terá que ser substituída - ou alterada, ou inventada, ou reinventada. Moreira Campos sempre nos surpreende com um enredo que se conta em algumas páginas, mas tão denso, tão cortante eu diria, capaz de resumir toda situação dramática em duas frases acerbas; todo um esplendor de paisagem em três linhas (QUEIROZ, 1996, p. 8).

Pontes (2011) explica que tal inquietação formal vai culminar efetivamente na seleção dos temas e dos conflitos intrínsecas a um realismo quase documental, tanto se amparando do sentido subjacente às palavras e aos períodos na captação da realidade, quanto, como advertiu Fisher (1985, p. 49), na "abordagem direta, objetiva do problema, somando detalhes, minúcias que armam o verossímil”.

Ao analisar o conto Sentimento (1993) de Moreira Campos, temos a certeza que no rol da literatura cearense, esse escritor notabilizou-se consagrado pela crítica literária pelo realismo e gosto pelos acontecimentos sociais dos mais necessitados, pelo olhar profundo nas relações cotidianas humanas, sobretudo registrando os dramas, conflitos e desigualdades entre as pessoas.

Observemos a metaleitura feita pelo autor em relação a sua própria arte de fazer literatura, colocando o conto não como subgênero, mas como um texto literário repleto de recursos estilísticos que marcam a individualidade e a originalidade do autor. A esse ponto MC diz como brotaram seus contos 
[...] nenhum conto meu surge da fantasia. Há sempre um ponto verdadeiro, real que eu procuro transformar num conto. Se procuro transformar num conto, já estou compromissado com a arte literária, porque não é só contar o fato simplório, simples: Fulano de tal chegou em casa, viu a mulher em adultério, puxou o revólver... Isto não é arte, é registro policial. A arte tem outra dimensão, é recriação do real. Aí cabe ao autor ter capacidade para dar beleza, chamamento, é a recriação do real (CAMPOS, 1996, p. 89).

Dessa forma, compreende-se que os personagens dos contos de Moreira Campos são relacionados ao meio em que eles estão inseridos, sobretudo como funcionários públicos padecedores, assim como Alice nesse conto que estamos analisando as características de costume regionalista, seus traços caricaturais e os tormentos do dia-a-dia.

Observa-se também que a escrita de Moreira Campos, segundo Pereira (2011) não segue uma linearidade se considerarmos as duas fases em sua obra citadas. Na primeira observamos algumas características impressionistas. Primeiro, podemos notar que sua escrita começa adquirir certo realismo irônico, fortemente influenciado pela tradição machadiana. Contudo, como ressalva Monteiro (1980)

[...] em ambas as fases existe uma acentuada inclinação pela defesa de uma concepção de arte clássico-realista, defesa armada pelo prestígio da limpidez e equilíbrio da linguagem e pelo senso de captação do real, sem a profusão exacerbada de conteúdos subjetivos ou de sentimentalismo mórbidos (MONTEIRO, 1980, p. 15).

Pereira (2011) salienta que essas colocações do crítico conseguem destacar que as particularidades impressionistas contemporâneas na obra de Campos se materializam na desenvoltura e no gosto pela fortuna do apelo ao imaginativo-sensorial.

Aqui, no caso, evidencia-se o desenrolar de uma briga entre vizinhas devido às desavenças entre Nazira, filha de Alice de personalidade forte como o pai e Celina filha de D. Neide, intrigantezinha e teimosa, que brigam num jardim, é nesse desentendimento natural de crianças que Moreira Campos trabalha os aspectos "sentimentalóides" de Alice em relação às atitudes de D. Neide.

Primeiro, entende-se que Alice está inconformada e receosa de encontrar a mãe de Celina, pois quer evitar uma discussão já que o enfardo da repartição e dos atritos com sua 
vizinha tornavam mais sacrificada sua vida do trabalho para casa, vê-se isso nesse trecho: "com a brandura de modos, temente de escândalos, passinho miúdo nos sapatos altos, o apertado do coque na cabeça bem-feita, elegância de bolsa, já fazia uns quatro dias que ela descia próximo de casa. Sacrifício [...]" (CAMPOS, 1993, p. 348, grifos nossos).

Nessa passagem do conto Moreira Campos cria uma imagem literária de Alice como uma mulher de grandes cuidados com seus filhos, inclusive Carlinhos, ela tem ainda um complexo de relacionamento de pessimismo natural com os vizinhos e o trabalho, já que se preocupa em descer um quarteirão antes só para evitar o encontro com D. Neide.

A personagem Alice passa a criar um questionamento profundo sobre os acontecimentos de início com Nazira, que é briguenta na opinião de D. Neide. Seu filho mais velho Alfredo seria um dos motivos do seu sentimentalismo preocupante, pois educara os filhos com muitos conselhos e paciência.

Alice passa a indagar as atitudes fúteis da vizinha, D. Neide, que fazia questão de afrontá-la, comentando fofocas com atrevimento em querer brigar por desentendimentos de suas crianças. Alice a queria humilde e discreta, embora fosse difícil. Entretanto, Alice dramatiza como era possível, ela ser tão infortunada por uma tipa idiota, sentindo então uma revolta visto que D. Neide a esperava na porta para tomar satisfação.

A rotina de Alice foi exatamente essa um tormento em passar perto da casa de D. Neide e aguentar esse desrespeito, já que ela não se dava o luxo de viver de casa em casa, fofocando e criando desavenças. Embora, o problema para Alice fosse insuportável, ela fazia questão de manter a calma, a serenidade e o melhor sorriso ao se surpreender com o encontro com D. Neide que foi avisada por Celina.

D. Alice ao perceber que D. Neide pedi sua atenção para uma conversa decisiva, começa a se pacientar e, maleavelmente, a mostrar para a sua vizinha que aquela situação poderia ser resolvida apenas se esclarecendo os acontecidos entre as filhas que eram tão amigas.

Em suma, nesse desfecho narrativo, Moreira Campos constrói toda uma situação de expressões populares que faz com que D. Neide fique ressentida em tentar difamar uma mulher tão educada, pelo menos era o que demonstrava ao explicar a D. Neide que é melhor o entendimento entre elas. 


\section{CONSIDERAÇÕES FINAIS}

Por fim, percebe-se pela análise deste conto que D. Neide ao perceber o fracasso em atingir Alice com julgamentos triviais sobre sua vida e a forma de criação dos filhos, começou a chorar e a confessar para Alice que não era certo elas continuarem nessa desarmonia e o melhor era se esquecer as desavenças criadas pelas filhas e construírem um relacionamento mais compreensível e mútuo entre as famílias.

Conclui-se, portanto, que Alice no desenrolar do enredo cria em D. Neide um sentimento profundo de compreensão e amizade sincera, já que ela estava fazendo de tudo para evitar maiores transtornos para seus filhos e vizinhos e que a melhor opção era cada uma entender a situação e a personalidade de cada uma em relação a essas discórdias que eram comuns ali.

Coadunando com as ideias de Monteiro (1980), Albuquerque (1985); Melo (2009), Pontes (2011), Timbó \& Coutinho (2012), Elesbão \& Silva (2015), dentre outros, almejou-se com esse trabalho contribuir para a preservação da memória de Moreira Campos e, por extensão, do escritor cearense e das relações humanas e sociais efetivas pelas personagens de Alice e D. Neide no conto Sentimento (1993) e, ainda, contribuído para despertar o interesse pela pesquisa literária, colaborando com o desenvolvimento do gosto pela leitura (SILVA, 2015) e pelos estudos literários cearenses.

\section{REFERÊNCIAS}

ALBUQUERQUE, Antônia Lucineide de Pessoa. A versatilidade temática em Moreira Campos. In: Revista de Letras, Fortaleza, v. 8, n. 1, jan/jun. p. 151-165, 1985. Disponível em: 〈http://www.repositorio.ufc.br/bitstream/riufc/9429/1/1985_Art_ALPAlbuquerque.pdf> Acesso em: 30 jun. 2018.

CAMPOS, Moreira. Vidas Marginais. Fortaleza: Edições Clã, 1949.

CAMPOS, Moreira. Portas Fechadas. Rio de Janeiro: O Cruzeiro, 1957.

CAMPOS, Moreira. As vozes do morto. São Paulo: Francisco Alves, 1963.

CAMPOS, Moreira. O puxador de terço. Rio de Janeiro: José Olympio, 1969. 
CAMPOS, Moreira. Os doze parafusos. São Paulo: Cultrix, 1978.

CAMPOS, Moreira. Dizem que os cães vêem coisas. Fortaleza. EUFC, 1987.

CAMPOS, Moreira. Dizem que os cães vêem coisas: contos. São Paulo: Maltese, 1996.

CAMPOS, Moreira; BARROSO, Antônio Girão. MAIA, José Barros. In: Roteiro

Sentimental de Fortaleza: depoimentos de história oral de Moreira Campos, Antônio Girão Barroso e José Barros Maia. Fortaleza: Ed. UFC - NUDOC / SECULT, 1996. p. 23-102.

ELESBÃO, Juliane de Sousa; SILVA, Odalice de Castro. O cotidiano fatídico na narrativa de Moreira Campos. In: Revista Entrelaces, Ano IV, n. 05, p. 128-137, mai. 2015. Disponível em: <http://www.entrelaces.ufc.br/2015/entrelaces-2015-05.pdf> Acesso em: 20 jul. 2018.

FISCHER, Almeida. O áspero ofício VI. Brasília: Horizonte/ INL, 1985.

LEITE JÚNIOR, (José Leite de Oliveira Júnior). Depoimento pessoal na Palestra proferida na $30^{a}$ edição dos Encontros Literários Moreira Campos, tendo como temas as personagens do contista. In: Caderno 3 - Quem tem medo de Moreira Campos? Realizada em 24 mar. 2014. Disponível em: <http://diariodonordeste.verdesmares.com.br/cadernos/caderno3/quem-tem-medo-de-moreira-campos-1.880281> Acesso em: Acesso em: 29 de ago. 2018.

MELO, Terezinha Alves. Dizem que os cães vêem coisas [Manuscrito]: o transitar dos manuscritos. 144f. Dissertação (Mestrado em Letras e Literatura). UFC/PPGL, Fortaleza, 2009. Disponível em:

<http://www.repositorio.ufc.br/bitstream/riufc/3262/3/2009_DIS_TAMELO.pdf> Acesso em: 09 ago. 2018.

MONTEIRO, José Lemos. O discurso literário de Moreira Campos. Fortaleza: Edições UFC, 1980.

MORAES, Vera Lúcia Albuquerque de. Clã: trajetórias do modernismo em revista. Fortaleza: Demócrito Rocha, 2004, p. 99-103.

PEREIRA, Danglei de Castro. Ironia e crítica em “profanação". In: Revista Avepalavra. 11. ed., 2011. Disponível em:

$<$ http://www2.unemat.br/avepalavra/EDICOES/11/artigos/IRONIA\%20E\%20CRITICA\%20E M\%20PROFANACAO.pdf> Acesso em: 20 jul. 2018. 
PONTES, Carlos Gildemar. A dança dos pobres diabos: o idealismo neutralizado e a degradação dos personagens nos contos de Moreira Campos. 126f. Dissertação (Mestrado em Letras). UERN/PPGL, Pau dos Ferros, 2011.

QUEIROZ, Rachel de. Prefácio: In: CAMPOS, Moreira. Obras Completas - Conto I. (Org.). Natércia Campos. São Paulo: Maltese, 1996.

SILVA, Eduardo Dias da. Eu gosto do gosto de gostar de ler: a leitura como gênero discursivo na escola. In: E-scrita Revista do Curso de Letras da UNIABEU, Nilópolis, v. 6, n. 1, jan/abr., p. 230-243, 2015. Disponível em:

<http://revista.uniabeu.edu.br/index.php/RE/article/viewFile/1624/pdf_368> Acesso em: 10 ago. 2018.

SILVA, Eduardo Dias da. Atuação teatral e ensino de línguas estrangeiras. Jundiaí: Paco Editorial, 2017.

TIMBÓ, Margarida Pontes; COUTINHO, Fernanda Maria Abreu. A relação dialógica nos contos "Dizem que os cães veem coisas", de Moreira Campos, e "A Menina", de Natércia Campos. In: Revista Literatura em Debate, v. 6, n. 11, p. 32-52, dez. 2012. Disponível em: <revistas.fw.uri.br/index.php/literaturaemdebate/article/download/642/1191> Acesso em: 29 ago. 2018. 